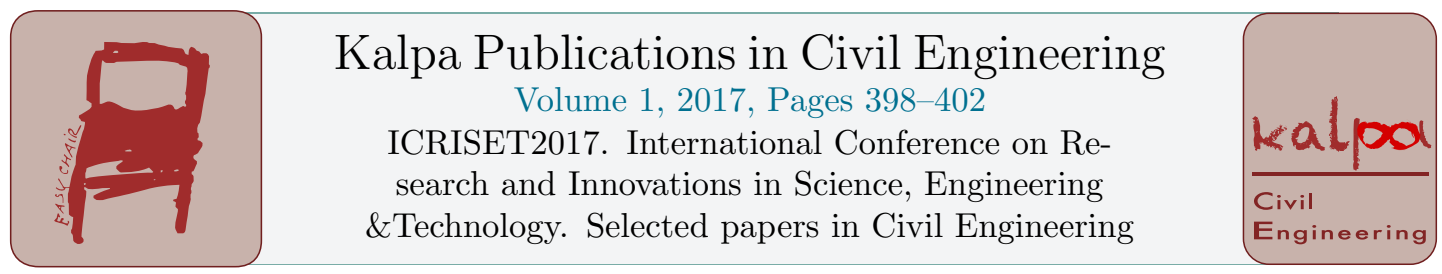

\title{
Micro-Irrigation: An Efficient Technology for India's Sustainable Agricultural Growth
}

\author{
Dr. Khadeeja Priyan ${ }^{1,2}$ and Ratansharan Panchal ${ }^{1,2}$ \\ ${ }^{1}$ Department of Civil Engineering \\ ${ }^{2}$ G H Patel College of Engineering \& Technology, Vallabh Vidyanagar, India. \\ khadeejapriyan@gcet.ac.in, ratanpanchal@gcet.ac.in
}

\begin{abstract}
India being an agrarian country, the present and future challenges of agricultural demand due to population increase can be met by technological innovations for sustainable agriculture. Indian agriculture beset with water scarcity and becomes less remunerative and uncertain. Since water being a precious resource for agriculture, every drop of water available for irrigation is significant for overall farm efficiency. Hence there is prudent and paramount need for efficient use of the available water and microirrigation is one such innovative technology. Economic return is very important for the adoption of any new technology. Economic return with more engineering approaches to keep water productivity more relevant in economic considerations [1]. Raising the physical productivity of water in crops without due considerations to economics will not have much relevance to small farmers in developing countries [2]. This paper assesses the current status and technologies of micro-irrigation and evaluating the future prospects of micro-irrigation adoption in India. The rationale of the paper is to appraise micro-irrigation as an innovative technology for sustainable agriculture in India and its significant impact on water productivity and land productivity.
\end{abstract}

\section{Introduction}

Water is a scarce natural resource and the major requirement of water is in agricultural sector. The water availability depends on various hydro-meteorological factors and therefore the efficient use of available water for irrigation is vital but a major challenge. Hence, technological innovations and interventions are essential for water development and management for sustainable agriculture. Since, water being a precious resource for agriculture, every drop of water available at delivery system and its proper utilization is very important for overall farm efficiency. Hence, there is prudent and paramount need for efficient use of the available water and micro-irrigation is one such innovative technology. Sprinkler irrigation and drip irrigation are the commonly used micro-irrigation methods. Economic return is an important parameter for the adoption of any new technology and at the same time productivity of land and water are also equally important. Hence, more engineering approaches are required to keep water productivity more relevant in economic considerations [1]. Efficient 
irrigation technologies ensure the real water saving in crop production of arid and semi arid regions in developing countries [2].

This paper assesses the current status and technologies of micro-irrigation and evaluating the future prospects of micro-irrigation adoption in India. The rationale of the paper is to appraise microirrigation as an innovative technology for sustainable agriculture in India and its significant impact on water productivity and land productivity.

\section{Micro-Irrigation: An Innovation Technology}

Water scarcity in various parts of the country has created awareness about micro-irrigation systems and its implementation results in significant economic and social benefits in the country. The benefits are noticed in terms of crop yields, reduction in energy consumption, reduction in the use of chemical fertilizers \& pesticides. It also ensures additional benefits like non-exploitation of groundwater, reduction in the cost of weeding and relief from water scarcity induced labour migration [3]. The real water saving can be obtained from the irrigation efficiency at field level. To improve the water productivity for agriculture, initiatives can be taken at field level and the saved water can be used for the irrigation of additional acreage or for environmental and social needs. Kumar et al. (2008) suggested various factors such as type of crop and the spacing between them, type of micro irrigation technology, soil type, climate and geo-hydrology for the real water saving through the use of micro-irrigation technologies.

IAI et al. (2016) conducted a study and stated that micro-irrigation is considered as an integral part of Pradhan Mantri Krishi Sinchayee Yojna (PMKSY) and they have listedmany advantages of this technology compared to conventional water application methods due to proximity and focussed application. These are: (i) Micro-irrigation technology ensures water use efficiency as much as 50$90 \%$. This can be achieved due to the fact that micro-irrigation helps to reduce conveyance losses, runoff, evaporation losses, seepage and deep percolation losses significantly. The saved water can be used to increase the area under irrigation or for the reclamation of degraded/ waste land; (ii) Since low flow rate is required, small wells can also be used as a source and it helps for energy savings upto $30.5 \%$. The potential savings in power may be utilized in other sectors. (iii) The direct application of fertilizers to the roots results in the saving in fertilizer consumption up to $28.5 \%$. This has a long term impact to achieve land productivity; (iv) The crop yield is increased and it was stated that the productivity for crops \& fruits is increased up to $42.4 \%$ and the increase in productivity for vegetables up to 52.7\%. This ensures good economic return for the better yields. (v) Farmers can judiciously add more new crops due to improved water scenario and it was estimated that as many as $30.4 \%$ farmers have done it; and (vi) More focussed and judicious use of water has resulted in the increase in farmers income. In the same study, the impact of micro-irrigation was studied in 13 different districts and it was found out that the highest percentage increase in farmers income was in Gujarat (68\%) and the average income of all 13 districts was as much as $42 \%$. Hence, micro-irrigation has been considered as an innovative technology for sustainable agricultural growth.

Local level studies are available for variety of crops from various parts of the country. A study conducted on Banana crop under drip irrigation and conventional irrigation methods in Dharwad, Karnataka showed that drip irrigated farmers had benefitted by water use efficiency, increased yield, better quality of produce, easy water application, reduced weed growth, reduction in labour, availability of subsidy etc [5].

Water productivity is considered as a performance indicator of irrigation compared to old concept of irrigation potential [1]. Water productivity can be defined as the ratio of actual yield achieved and the water actually used. In the case of micro-irrigation, the crop yield is increased and the amount of 
water required is very less compared to any conventional methods. Hence the water productivity will be increased significantly due to the increase in numerator and decrease in the denominator. The real water saving in arid and semi arid regions can be achieved in crop production through efficient irrigation technologies [2].

\section{Micro-Irrigation: Current Status}

According to the study by [4], the average penetration level of micro-irrigation in the country is $5.5 \%$ which is much less compared to other countries and only few States in India having the penetration level greater than the national average. These States are Haryana (16.3\%), Sikkim (10.8\%), Andhra Pradesh (10.4\%), Rajastan (9.3\%), Karnataka (8.5\%), Gujarat (8.1\%), Maharashtra (7.3\%) and Tamil Nadu (6.4\%). The penetration level in all other states is less than the national average level $5.5 \%$. As per this report, a steady growth rate of $9.6 \%$ is observed in micro-irrigation since 2005 and till recently sprinkler irrigation was shown highest growth rate compared to drip irrigation. In 2012, the area under sprinkler irrigation was Compound Annual Growth Rate (CAGR) $58.6 \%$ and the same under drip irrigation was CAGR $41.4 \%$ whereas out of the total area under micro-irrigation in 2015, area under sprinkler irrigation was CAGR $56.4 \%$ and under drip irrigation was CAGR 43.6\%. Hence, in the recent years (2012-15) there was a strong demand for drip irrigation and its growth rate (CAGR 9.85\%) during this period outweigh the growth rate

of sprinkler irrigation (CAGR6.6\%). At present, the area under micro-irrigation is only 7.97 Mha which is dismal compared to large rain fed area in India. The top five States in India for area under micro-irrigation are Rajastan (16.85 Mha), Maharashtra (12.71 Mha), Andra Pradesh (11.63 Mha), Karnataka (8.47 Mha) and Gujarat (8.29 Mha). The potential for micro-irrigation is estimated as 69.5Mhaand cereal crop tops in the list with 29.6 Mha. Seven States in the country were identified having potential for micro-irrigation is more than $80 \%$ and Gujarat is one of them. However, it will take long time to achieve this potential if the current target of achieving 0.5 Mha is adopted.

\section{Government Schemes Available for Micro-Irrigation}

Government of India has initiated micro-irrigation in 1992 and recognized as a thrust area in various Centrally Sponsored Schemes (CSS) since 2006. This was later upgraded by National Mission on Micro Irrigation (NMMI) during the period 2010 to 2014 and National Mission for Sustainable Agriculture (NMSA) in the year 2014-15. NMMI had a clear vision to promote micro-irrigation as a thrust area and hence the area under this technology was increased from 3.09 Mha in 1992 to 6.14 Mha in 2012. Under NMMI, some of the States Bihar, Karnataka, Orissa, Rajastan and Sikkim achieved more than $90 \%$ of the set targets (physical and financial) whereas Andhra Pradesh, Chattisgarh, Gujarat, Haryana, Maharashtra and Tamil Nadu achieved more than $70 \%$ of the target. The key strengths of the scheme were focus on micro-irrigation, longevity for a sustained period of time, greater efficiency due to single implementation agency, quality standards and provisions for after sales service and Government support for demonstration. The limitations of this scheme were inadequate subsidy, inefficient fund disbursement, land ceiling to $5 \mathrm{Ha}$ and no uniform implementation.

National Mission for Sustainable Agriculture (NMSA) implemented in the year 2014-15 had four components; (i) Rain fed area development, (ii) On-farm water management, (iii) Soil health management, and (iv) Climate change and sustainable agriculture. On-farm water management 
promotes efficient technologies and equipments and the main focus is on water use efficiency. Hence, micro-irrigation is considered as a component of on-farm water management. A total amount of 1111.82 crores had been allocated to on-farm water management under NMSA where

Gujarates share was 142 crores. The major strengths of this scheme were (i) to promote a sustainable agricultural system considering climate change aspects and (ii) to promote location specific agronomic activities. In this scheme also some shortcomings were noticed at the planning and implementation stages. These were (i) lack of focus as a single idea, (ii) incomplete guidelines and (iii) inefficiency in implementing the scheme.

„Pradhan Mantri Krishi Sinchayee Yojna (PMKSY) ${ }^{e c}$, a flagship scheme launched by Honourable Prime Minister in the year 2015 with two distinctive slogans for water management (i) "Har Khetko Pani" - Extension of Irrigation

Cover and (ii) "Per Drop More Crop" - Improving Water Use Efficiency. This Yojna focuses on all aspects of water development and management with micro-irrigation as an integral component. Micro-irrigation was granted an allocation of approximately Rs. 1075 crores to all 640 districts in India.

Some of the State Governments have taken keen initiative for the implementation of microirrigation and Gujarat Green Revolution Company Ltd (GGRC), a Public Private Partnership (PPP) model is one such initiative by Gujarat Government. GGRC was formed during vibrant Gujarat 2005 with equity shares by Gujarat State Fertilizers \& chemicals Ltd (GSFC), Gujarat Narmada Valley Fertilizer Company Ltd (GNFC) and Gujarat Agro Industries Corporation Ltd. (GAIC). GSFC and GNFC are having equal shares with equity $46 \%$ and GAIC has equity $8 \%$.

\section{Challenges for Adopting Micro-Irrigation Technology}

Though the technology has large potential and accrued benefits, according to the report published by [4], the national schemes initiated since 2006 could not be addressed the following important issues related to planning and implementation of the technology: (i) Inadequate focus on nationwide spreading of micro-irrigation technology;(ii) Inefficiency in implementation as the implementation agency was changed from a dedicated mission to a component part of NMSA under PMKSY. In many States, the released funds were not utilised properly due to the lack of implementation strategies; (iii) Lack of reliable guidelines and delay in Government orders; (iv) Unavailability of subsidy funds for installation as subsidy reduced from 50\% to $35 \%$ and allocation of funds under various schemes is declined; and (v) Difficulty in getting necessary supports from financial services. It was reported that a lower adoption rate due to the reduction in budget during the period (2013-16).

Meti (2012) conducted a study on Banana in Dharwad, Karnaka and stated the various constraints of adopting drip irrigation as (i) complicated application process of loan and delay in getting it, (ii) non availability of soluble fertilizers, (iii) inadequate supply of electricity, (iv) chocking of laterals and drippers (v) high capital investments (vi) inadequate follow up services by the drip agencies (vii) non availability of quality materials and damage of laterals by rodents. The policy and implementation strategies were to be revised for better penetration of this technology.

\section{Summary \& Conclusion}

The noted benefits due to micro-irrigation technology are increase in yield, improvement in the 
water use efficiency, reduction in the cost of water, fertilizers and manures and weed removal. All these added up in the increase in the overall economical benefits accrued due optimum utilization of water. Since the technology offers higher benefits like irrigation efficiency (50-90\%), fertilizer $(28.5 \%)$ and energy $(30.5 \%)$, [2] this technology is highly relevant and praise worthy. Microirrigation is an intervention to address various issues of agricultural growth and hence it is considered as a leveraging technology to sustainable agriculture. Farmers will adopt the technology if economic return is more. Hence economic considerations can be incorporated with more engineering approaches to keep water productivity more relevant in economic criteria [1].

\section{References}

[1] L. S. Pereira, "Relating Water Productivity and Crop Evapotranspiration M," - In: Lamaddalena, N. (ed.), Shatanawi, M. (ed.), Todorovic, M. (ed.), Bogliotti, C. (ed.), Albrizio, R (ed.). Water Use Efficiency and Water Productivity: WASAMED project. Bari: CIHEAM, Options Mediterraneennes: Serie B. Etudes et Recherches: N.57 31-49, 2007.

[2] M. Dinesh Kumar \& Jos C. Van Dam, "Drivers of change in agricultural water productivity and its improvement at basin scale in developing economies. Water International," DOI 10.1080/02508060.2013.793572, 2013.

[3] P. K. Viswanathan, \& C. Bahinipati, "Exploring the Socio-Economic Impacts of Microirrigation System (MIS): A Case Study of Public Tube Wells in Gujarat, Western India," SAWAS 5(1) - pp (1-25), 2015.

[4] Irrigation Association of India (IAI) \& Federation of Indian Chambers of Commerce \& Industry (FICCI) \& Grant Thornton India

LLP, "Accelerating Growth of Indian Agriculture: Micro-irrigation An Efficient SolutioStrategy paper - Future prospects of micro irrigation in India," 2016.

[5] C. B. Meti, "Studies on factors influencing the drip irrigation adoption, constraints and remedial measures to increase area under drip irrigation," Internat. J. Agric. Engg., 5(2): 236-239, 2012.

[6] GOI, "Dynamic Ground water Resources of India, Central Ground Water Board (CGWB)," Ministry of Water Resources, Government of India, 2005.

[7] M. D. Kumar, Turral H Sharma, B. Amaasinghe U \&O. P. Singh, Water saving and yield enhancing micro-irrigation technologies in India: When and where can they become best bet technologies?. In M. D. Kumar (Ed.), "Managing water in the face of growing scarcity, inequity and declining returns: Exploring fresh approaches, volume 1", Proceedings of the 7th Annual Partners Meet (pp 1-36). Hyderabad: IWMI - Tata Water Policy Research Program, ICRISAT, 2008.

[8] NABARD Consultancy Services Pvt. Ltd. (NABCONS) (2009). Executive Summary on Evaluation Study of Centrally Sponsored Scheme on Micro Irrigation. National Committee on Plasticulture Applications in Horticulture (NCPAH), Ministry of Agriculture, New Delhi. 